\section{Commentary: A longer agonal period in lungs donated after circulatory determination of death is a gamble worth taking}

\author{
Benjamin S. Bryner, MD, and John C. Haney, MD
}

The surgeon deciding whether to accept lungs donated after circulatory determination of death (DCDD) on behalf of their patient must do so with limited information. Declining lungs that have met initial criteria for transplant but have experienced an agonal period of compromised perfusion while the donor progresses to asystole is done to reduce the risk of posttransplant primary graft dysfunction (PGD). The duration from withdrawal of life support to circulatory arrest is an imperfect predictor of PGD, but remains the main criterion. In the song "The Gambler," popularized by the late Kenny Rogers, the titular character exhorts a novice poker player to "know when to hold 'em, know when to fold 'em." Similarly, after a prolonged agonal period, the surgeon must decide whether to transplant those lungs, or await better lungs. Qaqish and colleagues ${ }^{1}$ present important institutional data suggesting that it may be safe to "hold 'em" longer than is traditionally the case.

The authors grouped DCDD lungs into tertiles to represent rapid (0-20 minutes), intermediate (20-60 minutes) and late ( $>60$ minutes) progression to circulatory arrest. These tertiles were chosen to represent intuitive categories and also to maximize the (admittedly small) number in the late group. They did not find significantly different rates of PGD between these tertiles (or comparing DCDD lungs with those implanted after neurologic determination of death).

As the authors admit, their institution's experience may represent a singular clinical benefit that may not translate.

\footnotetext{
From the Division of Thoracic and Cardiovascular Surgery, Department of Surgery, Duke University, Durham, NC.

Disclosures: The authors reported no conflicts of interest.

The Journal policy requires editors and reviewers to disclose conflicts of interest and to decline handling or reviewing manuscripts for which they may have a conflict of interest. The editors and reviewers of this article have no conflicts of interest.

Received for publication May 25, 2020; accepted for publication May 25, 2020; available ahead of print June 6, 2020.

Address for reprints: Benjamin S. Bryner, MD, Division of Thoracic and Cardiovascular Surgery, Department of Surgery, Duke University, DUMC 3867, Durham, NC 27710 (E-mail: ben.bryner@duke.edu).

J Thorac Cardiovasc Surg 2021;161:1559-60

$0022-5223 / \$ 36.00$

Copyright (C) 2020 by The American Association for Thoracic Surgery

https://doi.org/10.1016/j.jtcvs.2020.05.079
}

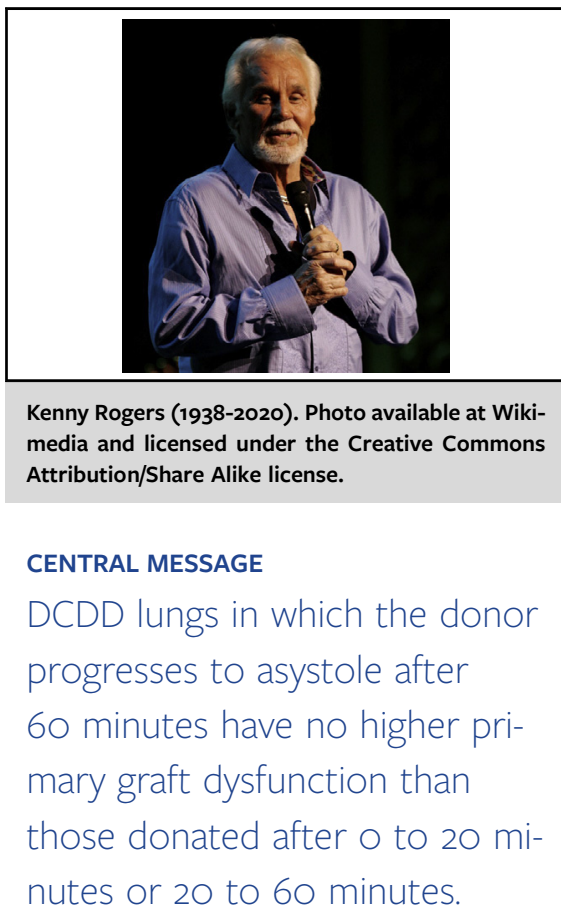

Besides their high volume of transplants, the authors' experience with ex vivo lung perfusion (EVLP) is a relevant confounder. (All lungs from the 20 donors who experienced arrest after 60 minutes were perfused with EVLP, as were $66 \%$ and $63 \%$ of those who experienced arrest in $<20$ minutes and 20-60 minutes, respectively.) The EVLP learning curve is formidable for both the safe operation of the EVLP platform and the interpretation of objective and subjective data that it generates.

A further limitation is the selection of the total time from withdrawal of life support to asystole as the interval to be studied. The initial postwithdrawal period may be characterized by near-normal oxygenation and hemodynamics. Indeed, the inclusion criteria for an ongoing study of DCDD heart donation includes an upper limit on the period between relative hypoxia and arrest, not the time from withdrawal of support. ${ }^{2}$ An extra 30 minutes of relatively normal perfusion may be less detrimental than, for example, $10 \mathrm{mi}-$ nutes of hypoxia, although this is difficult to study.

Many centers are already extending their cutoff time, likely emboldened by the Toronto group's aggressive acceptance policies: Several centers in the International Society for Heart and Lung Transplantation DCDD Registry allow up to 90 minutes for progression to asystole. ${ }^{3}$ Our own institution extends this time to 120 minutes.

At the operating table and the poker table, "the secret to survivin' / Is knowin' what to throw away / And knowin' what to keep." The authors present an avenue for expanding 
the donor pool by avoiding unnecessarily discarding lungs after slow donor progression to asystole.

\section{References}

1. Qaqish R, Watanabe Y, Hoetzenecker K, Yeung J, Chen M, Pierre A, et al. Impact of donor time to cardiac arrest in lung donation after circulatory death. J Thorac Cardiovasc Surg. 2021;161:1546-55.e1.
2. US National Library of Medicine Clinical Trials Registry. Donors after Circulatory Death Heart trial. Available at: https://clinicaltrials.gov/ct2/show/ NCT03831048. Accessed May 18, 2020.

3. Cypel M, Levvey B, Van Raemdonck D, Erasmus M, Dark J, Love R. International Society for Heart and Lung Transplantation Donation after Circulatory Death Registry Report. J Heart Lung Transplant. 2015;4: 1278-82.
See Article page 1546.

\section{Commentary: Adding sand to the hourglass}

\section{Sudish C. Murthy, MD, PhD, FACS, FCCP}

When considering valuable medical commodities, donor lungs are near the top of the list. Demand is often the principal driver of value, but resource scarcity is definitely a co-conspirator. The value of a lung allograft is seemingly driven up daily by both, and Qaqish and colleagues ${ }^{1}$ now suggest possible relief on the supply side of the equation.

The problem is not that complex: The number of lung transplant candidates being listed exceeds the number of organs available. Because of this, listed candidates die while waiting for organs. Of eligible organ donors, a mere $20 \%$ prove suitable for lung donation (in contrast to triple that for kidney and liver transplants), which perpetuates the problem.

Ever the pioneers, lung transplant practitioners have not sat idly on the sidelines accepting this shortfall. Among recent novel strategies, use of donors from circulatory determination of death (DCDD) provides a previously untapped source of organs in addition to the classic donors from neurologic death. DCDD represents a different paradigm in organ procurement with far less control of timing of procurement, warm ischemia, and aspiration protection. Yet this new cache of organs, despite liabilities, performs

From the Department of Thoracic and Cardiovascular Surgery, Heart, Vascular, and Thoracic Institute, Cleveland Clinic, Cleveland, Ohio.

Supported by the Cleveland Clinic and in part by the Daniel and Karen Lee Endowed Chair in Thoracic Surgery.

Disclosures: The author reported no conflicts of interest.

The Journal policy requires editors and reviewers to disclose conflicts of interest and to decline handling or reviewing manuscripts for which they may have a conflict of interest. The editors and reviewers of this article have no conflicts of interest.

Received for publication July 7, 2020; revisions received July 7, 2020; accepted for publication July 10, 2020; available ahead of print July 15, 2020.

Address for reprints: Sudish C. Murthy, MD, PhD, FACS, FCCP, Department of Thoracic and Cardiovascular Surgery, Cleveland Clinic, 9500 Euclid Ave, Desk J4-1, Cleveland, OH 44195 (E-mail: murthys1 @ ccf.org).

J Thorac Cardiovasc Surg 2021;161:1560-1

$0022-5223 / \$ 36.00$

Copyright (c) 2020 by The American Association for Thoracic Surgery

https://doi.org/10.1016/j.jtcvs.2020.07.033

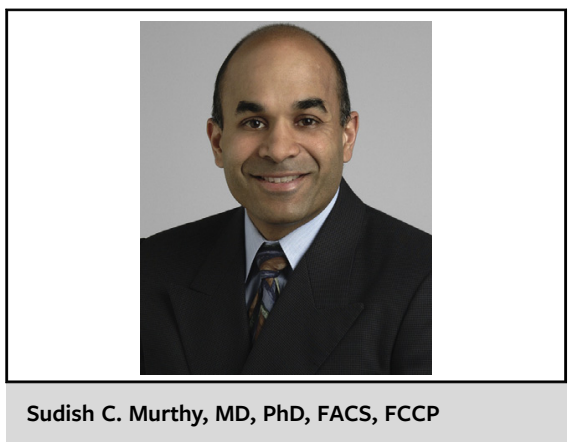

CENTRAL MESSAGE

Not every DCDD organ can be

pushed out beyond 60 minutes, and risks for organ demise after

extended asystole are still

undetermined.

admirably, with outcomes virtually indistinguishable from donors with neurologic determination of death. ${ }^{2}$

An impediment to broad dissemination of DCDD organs is uncertainty about which DCDD designates will actually donate! In other words, prospective donors become actual donors when they die within 60 minutes of separation from mechanical ventilation.

Why 60 minutes and not 30, 90, or 120 ? There is some science, but I suspect the answer is more of a theoretical concern about protracted hypoperfusion occurring while the harvesting team is waiting for cardiac standstill (asystole) after ventilator separation somehow deleteriously affecting the allograft. These patients, unlike donors dying from neurologic causes, do have some brainstem activity, and a respiratory drive is often apparent even after ventilator separation. The heart can continue beating for a surprisingly lengthy period in the presence of hypoxia, hypercardia, and 